\title{
Grapefruit peelings as a promising biosorbent for the removal of leather dyes and hexavalent chromium
}

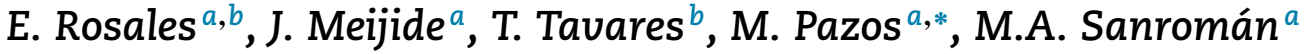 \\ a Department of Chemical Engineering, University of Vigo, Isaac Newton Building, Campus As Lagoas-Marcosende, \\ 36310 Vigo, Spain \\ b Centro de Engenharia Biológica, Universidade do Minho, Campus de Gualtar, 4710-057 Braga, Portugal
}

\section{A R T I C L E I N F O}

\section{Article history:}

Received 15 March 2015

Received in revised form 15

December 2015

Accepted 7 March 2016

Available online 16 March 2016

\section{Keywords:}

Grapefruit peelings

Adsorption

Tannery effluent

$\mathrm{H}_{2} \mathrm{O}_{2}$

Pretreatment

\begin{abstract}
A B S T R A C T
The objective of this study was to find a suitable and versatile agroforestry waste as alternative low-cost biosorbents for the removal of inorganic and organic compounds present in the wastewater of tannery industry [leather dyes and $\mathrm{Cr}(\mathrm{VI})]$. Grapefruit peelings, fern, eucalyptus barks, oak leaves and cane pruning of grapevines were evaluated as biosorbents. Among them, grapefruit peelings showed the best results reaching 45 and $55 \%$ for the mixture of dyes and $\mathrm{Cr}(\mathrm{VI})$, respectively. A significant improvement in the performance of this biosorbent was obtained when it was pretreated with $\mathrm{H}_{2} \mathrm{O}_{2}(1 \mathrm{M})$ attaining the highest removal capacity of $80 \%$ and $100 \%$, respectively. This biosorbent was characterised showing an adsorption capacity of $1.1003 \mathrm{meq} / \mathrm{g}$ and $\mathrm{pH}_{\mathrm{ZPC}} 3.48$. The adsorption working parameters, kinetics and isotherms were deeply studied in order to scale up the process to a continuous treatment system. Adsorption isotherms data fitted well to the Langmuir model with a maximum uptake of $37.427 \mathrm{mg} / \mathrm{g}$ for dyes mixture and $39.0628 \mathrm{mg} / \mathrm{g}$ for $\mathrm{Cr}(\mathrm{VI})$. Finally, the dynamic behaviour of the system, operating at different flow rates, was evaluated using a Homogeneous Surface Diffusion Model. Pretreated grapefruit peelings demonstrated to be a suitable low-cost biosorbent in the treatment of wastewater of tannery industry.

(c) 2016 Institution of Chemical Engineers. Published by Elsevier B.V. All rights reserved.
\end{abstract}

Abbreviations: HSDM, Homogeneous Surface Diffusion Model; CP, cane pruning wine grapes; EL, eucalyptus barks; FR, fern; GP, grapefruit peelings; OL, oak leaves; DM, leather dyes mixture; $C_{i}$, initial pollutant concentration of solution $(\mathrm{mg} / \mathrm{L}) ; C_{e}$, concentration of pollutant at adsorption equilibrium $(\mathrm{mg} / \mathrm{L}) ; C_{t}$, concentration of pollutant at time $\mathrm{t}(\mathrm{mg} / \mathrm{L}) ; \mathrm{D}$, removal of $\mathrm{DM}$ or $\mathrm{Cr}(\mathrm{VI})(\%)$; $\mathrm{V}$, volume $(\mathrm{mL}) ; m_{\text {ads }}$, mass of biosorbent (g); $q_{e}$, equilibrium adsorption capacity of biosorbent (mg/g); $q_{t}$, amount of pollutant adsorbed per unit of biosorbent at time $t(\mathrm{mg} / \mathrm{g}) ; t$, time $(\mathrm{min}) ; q_{\max }$, maximum pollutant uptake $(\mathrm{mg} / \mathrm{g}) ; b_{\mathrm{L}}$, Langmuir model affinity between the adsorbate and biosorbent $(\mathrm{L} / \mathrm{mg}) ; r^{2}$, linear correlation coefficient; $K_{\mathrm{F}}$, Freundlich model binding capacity $\left(\mathrm{mg}^{1-\left(1 / \mathrm{n}_{\mathrm{F}}\right)} \mathrm{L}^{1 / n_{\mathrm{F}}} / \mathrm{g}\right) ; n_{\mathrm{F}}$, Freundlich model affinity between the biosorbent and adsorbate; $K_{\mathrm{RP}}$, Redlich-Peterson model isotherm constant (L/g); $a_{\mathrm{RP}}$, Redlich-Peterson model constant $(\mathrm{L} / \mathrm{mg})^{\beta_{\mathrm{RP}}} ; \beta_{\mathrm{RP}}$, Redlich-Peterson model exponent; $K_{S}$, Sips model isotherm constant $\left(\mathrm{L}^{\beta_{S}} \mathrm{mg}^{1-\beta_{\mathrm{S}}} / \mathrm{g}\right) ; a_{\mathrm{S}}$, Sips model constant $\left(\mathrm{L}^{\beta_{\mathrm{S}}} / \mathrm{mg}^{\beta_{S}}\right) ; \beta_{\mathrm{S}}$, Sips model exponent; $k_{1}$, pseudo-first order rate constant $(1 / \mathrm{min}) ; k_{2}$, pseudo-second order rate constant $[\mathrm{g} /(\mathrm{mg} \min )]$; $k_{\mathrm{id}}$, intra-particle diffusion rate constant $\left[\mathrm{mg} /\left(\mathrm{g} \mathrm{min}^{1 / 2}\right)\right]$; I, intra-particle diffusion rate parameter; $\varepsilon$, porosity; $\rho_{\mathrm{p}}$, particle density $(\mathrm{g} / \mathrm{mL}) ; d_{\mathrm{p}}$, particle diameter $(\mathrm{mm})$; $\mathrm{Q}$ flow rate $(\mathrm{L} / \mathrm{min}) ; \mathrm{h}$, column height; $D_{\mathrm{C}}$, column diameter $(\mathrm{m}) ; \mathrm{V}_{\mathrm{C}}$, column volume $(\mathrm{L}) ; K_{\mathrm{L}}$, film diffusion coefficient $(\mathrm{L} / \mathrm{mg}) ; D_{\mathrm{s}}$, surface diffusion coefficient $\left(\mathrm{m}^{2} / \mathrm{s}\right)$.

* Corresponding author. Tel.: +34 986 818723; fax: +34 986812380

E-mail addresses: emiliorv@uvigo.es (E. Rosales), jmeijide@uvigo.es (J. Meijide), ttavares@deb.uminho.pt (T. Tavares), mcurras@uvigo.es (M. Pazos), sanroman@uvigo.es (M.A. Sanromán). 


\section{Introduction}

Industrial processes generate a wide range of wastewaters containing different pollutants that may involve either organic or inorganic reagents once used. Large amount of these pollutants arrive daily to both groundwater and surface water.

Tannery industries wastes present an important environmental impact on waters (Mwinyihija, 2010). Dyes and heavy metals such as chromium have been widely used in these industries (Rosales et al., 2012). Cr(VI) is a recognised carcinogenic and mutagenic agent and the presence at concentrations exceeding $0.05 \mathrm{mg} / \mathrm{L}$ for $\mathrm{Cr}(\mathrm{VI})$ (Acar and Malkoc, 2004) and $5.0 \mathrm{mg} / \mathrm{L}$ for Cr(III) (Acar and Malkoc, 2004; Pérez Marín et al., 2009) may be toxic for aquatic life. Dyes presence in water is undesirable due to the lasting colour, the increase in the chemical oxygen demand and the effect in the microorganisms present in the water streams.

Adsorption is one of the most commonly used techniques due to the easiness of design, operational simplicity and good efficiency in the removal of pollutants (Rosales et al., 2015; Crini, 2006). In the last years, the utilisation of wastes derived from agriculture or forestry has attracted the attention of the researchers due to their availability, biodegradability and inexpensive cost. Moreover, to improve the adsorption of organic and inorganic compounds, several pretreatments of the biosorbents have been proposed. Among the different pretreatments, several compounds such as $\mathrm{NaOH}, \mathrm{CaCl}_{2}$, organic acids (citric acid, oxalic acid), inorganic acids $(\mathrm{HCl}$, $\mathrm{H}_{2} \mathrm{SO}_{4}$ and $\mathrm{HNO}_{3}$ ) or $\mathrm{H}_{2} \mathrm{O}_{2}$ (Daffalla et al., 2012; Cobas et al., 2014; Shen et al., 2011) have been used. However, these biosorbents have been developed for the treatment of a specific target compound (organic or inorganic). According to the literature, different biosorbents have been proposed as alternative to more expensive and widely applied activated carbon. Thus, sawdust, husk rice, orange peelings, chestnut, hazelnut, peanut, cabbage, maize, Colocasia esculenta or grapefruit peelings have been proposed for metal removal (Rosales et al., 2015; Torab-Mostaedi et al., 2013; Hossain et al., 2014; Xu et al., 2014; Guyo et al., 2015; Pakshirajan et al., 2013) and peat, straw, sugarcane bagasse, orange or lemon peelings (Crini, 2006; Cobas et al., 2014; Bhatnagar et al., 2009; Gupta et al., 2009) for dye adsorption. However, there is a lack of biosorbents that can be efficiently applied for both inorganic and organic pollutants. Few studies have been developed in this field. Recently, a study developed in our laboratory demonstrated the feasibility of the biosorbent Fucus vesiculosus for the removal of both types of contaminants (Cobas et al., 2014).

The aim of this study is to find a versatile low-cost biosorbent for removing the typical pollutants present in the tannery effluents, $\mathrm{Cr}(\mathrm{VI})$ and mixture of commercial leather dyes. For that, several agroforestry wastes (grapefruit peelings, fern, eucalyptus barks, oak leaves and cane pruning of grapevines) were evaluated. The best biosorbent was studied in depth (kinetics and isotherms) in order to model and scale up its behaviour operating in a pilot scale column at different flow rates.

\section{Material and methods}

\subsection{Reagents}

Four leather dyes (Sella Solid Blue, Special Violet, Derma Burdeaux and Sella Solid Orange) were provided by a local tannery industry, Padronesa Industrial de Curtidos S.A. (Spain). The leather dyes mixture (DM), employed in all the experiments, was composed of a mixture of selected dyes in equal proportion. $\mathrm{Cr}(\mathrm{VI})$ as potassium dichromate was purchased from Panreac, and $\mathrm{H}_{2} \mathrm{O}_{2}$ (37\%) was purchased from Merck. All the used chemicals were reagent grade.

\subsection{Wastes}

\subsubsection{Biosorbents}

The selected wastes, grapefruit peelings (GP), fern (FR), eucalyptus barks (EL), oak leaves (OL) and cane pruning of grapevines (CP), were provided by a local supplier. The lignocellulosic composition of the selected wastes is shown in Table 1. The wastes were washed with distilled water three times and then dried in an oven at $60^{\circ} \mathrm{C}$ for $24 \mathrm{~h}$. Afterwards, the dried wastes were grinded using a cutting mill Retsh SM100 until a size minor than $0.5 \mathrm{~mm}$.

\subsubsection{Pretreatment of biosorbents}

The grapefruit peelings were pretreated using $\mathrm{H}_{2} \mathrm{O}_{2}$ according to Shen et al. (2011). Briefly, $1.5 \mathrm{~g}$ of biosorbent and $150 \mathrm{~mL}$ of $\mathrm{H}_{2} \mathrm{O}_{2}(1 \mathrm{M})$ were added to an $250 \mathrm{~mL}$ Erlenmeyer flask and stirred at $110 \mathrm{rpm}$ for $24 \mathrm{~h}$. These wastes were dried and grinded following the procedure described in the previous section.

\subsubsection{Biosorbent characterisation}

2.2.3.1. Scanning electron microscopy and energy dispersive spectrometry. Scanning electron microscopy and energy dispersive spectrometry (SEM/EDS) were performed on a JEOL JSM-6700F SEM equipped with an EDS Oxford Inca Energy 300 SEM using an accelerating voltage of $15 \mathrm{kV}$ (Electron Microscopy Service, C.A.C.T.I., University of Vigo).

2.2.3.2. Fourier-transform infrared spectra. Fourier-transform infrared (FT-IR) spectra of the biosorbents were recorded on an FT-IR spectrometer (model FT-IR/4100, Jasco). Previously, the GP samples before and after adsorption processes were dried in an oven at $60^{\circ} \mathrm{C}$ for $40 \mathrm{~min}$.

2.2.3.3. Functional group evaluation. The acidic and basic oxygen surface functional groups distribution was measured via Boehm titration procedure (Boehm, 1966). The experiments were carried out in $250 \mathrm{~mL}$ Erlenmeyer flasks containing $1 \mathrm{~g}$ of pretreated biosorbent and $50 \mathrm{~mL}$ of $0.1 \mathrm{~N}$ solutions $\left(\mathrm{NaHCO}_{3}\right.$, $\mathrm{Na}_{2} \mathrm{CO}_{3}, \mathrm{NaOH}$ or $\mathrm{HCl}$ ). The mixture was shaken in an incubator (Thermo scientific MaxQ800) for $24 \mathrm{~h}$ at room temperature, and then the supernatant was filtered to remove particles and back-titrated using an acid-base indicator. The number of acidic sites were calculated under the assumption that $\mathrm{NaOH}$ neutralises carboxyl, phenolic and lactonic groups, $\mathrm{Na}_{2} \mathrm{CO}_{3}$, carboxyl and lactonic and $\mathrm{NaHCO}_{3}$ only carboxyl groups. The number of basic sites was calculated under the assumption that $\mathrm{HCl}$ neutralises the basic groups.

2.2.3.4. Point of zero charge. The point of zero charge ( $\left.\mathrm{pH}_{\mathrm{PZC}}\right)$ was determined by mass titration (Noh and Schwarz, 1989). Briefly, $1 \mathrm{~g}$ of biosorbent was contacted for $24 \mathrm{~h}$ with $50 \mathrm{~mL}$ of $\mathrm{NaNO}_{3}$ as background electrolyte at several different $\mathrm{pH}$ values within the range of 2 to 8 . The solution $\mathrm{pH}$ was adjusted with diluted $\mathrm{HNO}_{3}$ and $\mathrm{NaOH}$ up to achieve desired values. The $\mathrm{pH}$ supernatant was measured with a Jenway $3520 \mathrm{pH}$ Meter after three-point calibration. 
Table 1 - Lignocellulosic composition of the selected biosorbents.

\begin{tabular}{lccll} 
Biosorbent & Cellulose (\%) & Hemicellulose (\%) & Lignin (\%) & Reference \\
\hline Cane pruning & 49.40 & 15.82 & 14.69 & Gaitán-Hernández et al. (2011) \\
Eucalyptus bark & 56.9 & 23.7 & 16.9 & Miranda et al. (2012) \\
Fern & 34 & 34 & 35.2 & Carrier et al. (2012) \\
Oak leaves & 25.1 & 12.3 & 11.3 & Mediavilla et al. (2008) \\
Grapefruit peelings & 20.75 & 17.34 & $\mathrm{n} / \mathrm{a}$ & Ng et al. (2014) \\
\hline
\end{tabular}

2.2.3.5. Esterification/methylation. To determine the functional groups involved in the binding process, several chemical surface modifications were investigated in batch experiments (Gardea-Torresdey, 1990; Deshkar et al., 1990). The esterification of carboxyl groups by acidic methanol and the methylation of hydroxyl and phenolic groups with formaldehyde allowed a selective blocking of these functional groups with subsequent variation of dyes and chromium adsorption ability.

\subsection{Experimental setup}

The adsorption assays were performed in Erlenmeyer flasks $(250 \mathrm{~mL})$ containing different amounts of biosorbents (0.3-1.5 g) in $50 \mathrm{~mL}$ of the pollutant solution to consider [DM or $\mathrm{Cr}(\mathrm{VI})]$ at natural $\mathrm{pH}$ 5.5. The flasks were shaken in an incubator (Thermo scientific MaxQ800) at $120 \mathrm{rpm}$ and $25^{\circ} \mathrm{C}$.

Adsorption kinetic studies were made at initial concentrations of 200 or $35 \mathrm{mg} / \mathrm{L}$ for DM and Cr(VI), respectively, whereas adsorption equilibrium isotherms were evaluated with concentration ranging from 15 to $100 \mathrm{mg} / \mathrm{L}$ for $\mathrm{Cr}(\mathrm{VI})$ and 100 to $400 \mathrm{mg} / \mathrm{L}$ for DM.

The experiments lasted $24 \mathrm{~h}$ and were carried out in duplicate, and liquid aliquots $(1 \mathrm{~mL})$ were taken along the time for measurements of concentration. All samples were centrifuged at $10,000 \mathrm{rpm}$ for $5 \mathrm{~min}$, and the supernatant was separated to analyse the pollutant removal. All experiments were carried out in duplicate, and the standard deviation (SD) was less than $5 \%$. The maximum percentage error of the data is $\leq 3.5$ (3.3574\%) in all the experiments. Shapiro-Wilk normality tests were performed in the nonlinear regressions used for fitting data to kinetic and isotherm models. In all cases, the tests were passed with a significance level $\leq 0.0001$ and $\leq 0.05$ for $\mathrm{DM}$ and $\mathrm{Cr}(\mathrm{VI})$, respectively.

\subsection{Analytical procedures}

\subsubsection{Dye measurement}

The dye content was measured spectrophotometrically. The concentration was determined based on the area under the curve at a wavelength range between $400 \mathrm{~nm}$ and $750 \mathrm{~nm}$. Samples were diluted with distilled water when the absorbance exceeded the range of the calibration curve.

\subsection{2. $\mathrm{Cr}(\mathrm{VI})$ determination}

Chromium concentration in supernatant was determined by spectrophotometric methods. $\mathrm{Cr}(\mathrm{VI})$ was quantified by measuring absorbance at $540 \mathrm{~nm}$ of the purple complex of $\mathrm{Cr}(\mathrm{VI})$ with 1,5-diphenylcarbazide in acidic solution.

\subsubsection{Leather dyes mixture and $\mathrm{Cr}(\mathrm{VI})$ adsorption uptake} and removal percentages

The amount of $\mathrm{DM}$ or $\mathrm{Cr}(\mathrm{VI})$ adsorbed $\left(q_{\mathrm{t}}\right)$ and their removal percentages $(D)$ were calculated using the following equations:

$$
\begin{aligned}
& D=100 \cdot \frac{\left(C_{i}-C_{t}\right)}{C_{i}} \\
& q_{t}=\frac{\left(C_{i}-C_{t}\right) V}{m_{\text {ads }}}
\end{aligned}
$$

\subsection{Adsorption isotherm}

The adsorption isotherms are important in describing interactions between adsorbate molecules and biosorbent surface and their distribution between the liquid and the solid phases in an equilibrium state. Different well-known models with two or three fitting parameters can be used. Among them, Langmuir, Freundlich, Sips and Redlich-Peterson were chosen (Rosales et al., 2012; Vijayaraghavan and Yun, 2008).

\subsubsection{Two-parameter models}

2.5.1.1. Langmuir isotherm. Langmuir isotherm assumes that all sorption sites are energetically equivalent, identical and the biosorbent is structurally homogeneous. The model can be expressed according to the following expressions:

$q=\frac{q_{\max } \cdot b_{\mathrm{L}} \cdot C}{\left(1+b_{\mathrm{L}} \cdot C\right)}$

where $q_{\max }$ (mg pollutant $\left./ g_{\text {biosorbent }}\right)$ is the maximum uptake achievable, and $b_{\mathrm{L}}\left(\mathrm{L} / \mathrm{mg}_{\text {pollutant }}\right)$ represent the affinity adsorbate-biosorbent.

2.5.1.2. Freundlich isotherm. The Freundlich isotherm was obtained empirically, being used for heterogeneous systems, describing the sorption of ions by chemical adsorption and surface precipitation reactions. The binding strength decreases when the adsorption degree increases. The isotherm can be represented as

$q=K_{F} \cdot C^{1 / n_{F}}$

where $K_{\mathrm{F}}\left(\mathrm{mg}_{\text {pollutant }}{ }^{1-\left(1 / n_{\mathrm{F}}\right)} \mathrm{L}^{1 / n_{\mathrm{F}}} / \mathrm{g}_{\text {biosorbent }}\right)$ is the binding capacity, and $n_{F}$ characterises the biosorbent-adsorbate affinity.

\subsubsection{Three-parameter models}

Different three-parameter models have also been widely considered for the description of the adsorption isotherms. Among them, those that combine the Langmuir and Freundlich models such as Redlich-Peterson and Sips were selected:

2.5.2.1. Sips isotherm. The Sips model predicts a monolayer sorption capacity for high adsorbate concentrations, typical of Langmuir isotherm, and reduces to Freundlich isotherm for low adsorbate concentrations.

$q=\frac{K_{S} \cdot C^{\beta_{S}}}{\left(1+a_{S} \cdot C^{\beta_{S}}\right)}$ 


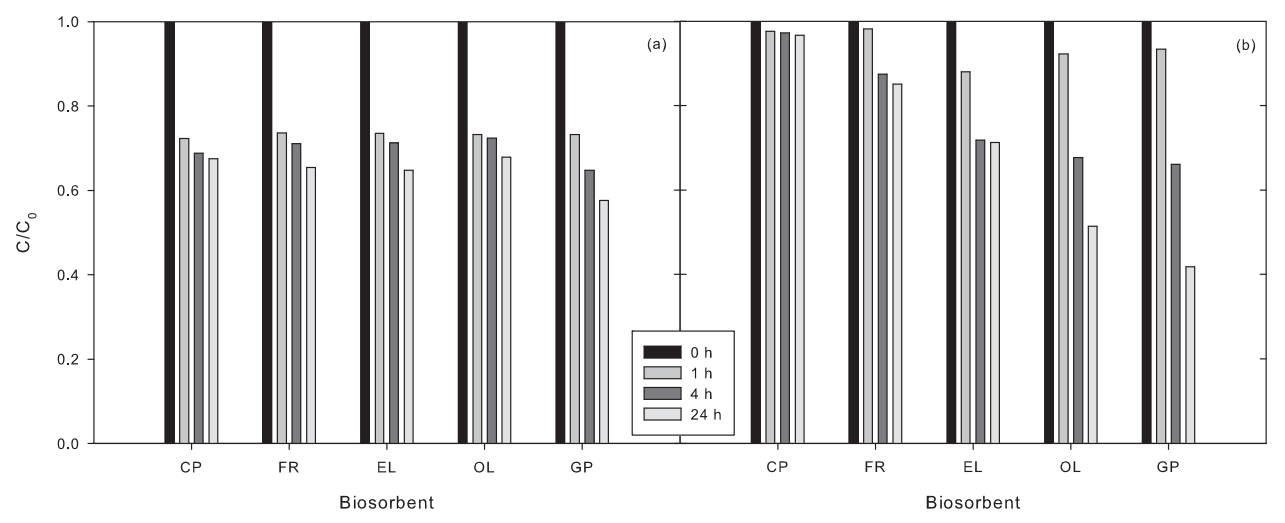

Fig. 1 - Removal ability of different biosorbents along the time: (a) DM and (b) $\mathrm{Cr}(\mathrm{VI})$. Initial conditions: $\mathrm{Cr}$ (VI) concentration $35 \mathrm{mg} / \mathrm{L}$; DM concentration $200 \mathrm{mg} / \mathrm{L}$; biosorbent $1 \mathrm{~g}$.

where the Sips model constant are $K_{S}$ $\left(\mathrm{L}^{\beta_{\mathrm{S}}} \mathrm{mg}_{\text {pollutant }}{ }^{1-\beta_{\mathrm{S}}} / \mathrm{g}_{\text {biosorbent }}\right)$ and $a_{\mathrm{S}}\left(\mathrm{L}^{\beta_{\mathrm{S}}} / \mathrm{mg}_{\text {pollutant }}{ }^{\beta_{\mathrm{S}}}\right)$ and the Sips model exponent is $\beta_{\mathrm{S}}$.

2.5.2.2. Redlich-Peterson isotherm. In the case of the Redlich-Peterson model, it is used as a compromise between Langmuir and Henry models. In this model, it comprises an exponent $\beta_{\mathrm{RP}}$ which varies between 0 and 1 showing two limiting behaviours: the expression simplifies to Langmuir model for $\beta_{\mathrm{RP}}=1$ and Henry's law form for $\beta_{\mathrm{RP}}=0$.

$q=\frac{K_{\mathrm{RP}} \cdot C}{\left(1+a_{\mathrm{RP}} \cdot C^{\beta_{\mathrm{RP}}}\right)}$

where the model constants are $K_{\mathrm{RP}}$ ( $\mathrm{L} /$ gbiosorbent $_{\text {b }}$ ) and $a_{\mathrm{RP}}$ $\left(\mathrm{L}^{\beta_{\mathrm{RP}}} / \mathrm{mg}_{\text {pollutant }} \beta_{\mathrm{RP}}\right)$, and $\beta_{\mathrm{RP}}$ is the model exponent.

\subsection{Breakthrough model}

The modelling of the breakthrough curve was developed using FAST Fixed-bed Adsorption Simulation Tool v2.1 (Sperlich et al., 2008). This software was developed based on the Homogeneous Surface Diffusion Model (HSDM) with the following assumptions: (1) one-dimensional plug-flow, (2) the biosorbent particles behave as a pseudo-homogeneous medium wherein the pollutant diffuses, (3) external mass-transfer limitation is accounted for and (4) adsorption equilibrium prevails at the fluid-solid external surface (Richard et al., 2010).

The application of HSDM (Pérez-Foguet et al., 2013; Walker, 2015; Zhang et al., 2009), using FAST Fixed-bed Adsorption Simulation Tool v2.1 (http://www.fast-software.de/), requires the following input parameters: the biosorbent characteristics, operational conditions, isotherm data (Freundlich or Langmuir constants) and mass transfer coefficients which are determined by empirical correlation in terms of the dimensionless numbers.

\section{Results and discussion}

\subsection{Screening of biosorbents}

Several agricultural and forestry wastes have been recognised as an environmental problem. For this reason, new gateways such as the production of renewable, low-cost and sustainable biosorbents for water treatment applications have been studied for these lignocellulosic biomass-rich materials (Bhatnagar et al., 2015). Due to the interest in this topic, in this study, several low-cost biosorbents from agroforestry wastes were evaluated for the removal of $\mathrm{DM}$ and $\mathrm{Cr}(\mathrm{VI})$ from aqueous solution (Fig. 1). All the biosorbents showed a DM removal percentage ranging from 30 to $40 \%$ reaching a maximum value of $42.5 \%$ using GP as biosorbent, and the lowest value was obtained for OL. On other hand, $\mathrm{Cr}(\mathrm{VI})$ removal varied considerably with the different biosorbents used. Thus, $\mathrm{CP}$ showed the worst removal ability with values lower than $4 \%$, whereas GP and OL were considered the best biosorbents reaching $\mathrm{Cr}(\mathrm{VI})$ removal levels of $58.6 \%$ and $48.8 \%$, respectively.

Among the tested biosorbents, GP was found the most efficient to remove both pollutants owing to its highest adsorptive capacity. The ability of GP to adsorb heavy metals was also reported to Torab-Mostaedi et al. (2013), who obtained adsorption capacities of 42.09 and $46.13 \mathrm{mg} / \mathrm{g}$ for $\mathrm{Cd}(\mathrm{II})$ and $\mathrm{Ni}(\mathrm{II})$, respectively. On the other hand, previous studies indicated an efficient adsorption of model dyes onto GP. Saeed et al. (2010) reached $96 \%$ crystal violet removal in $60 \mathrm{~min}$, whereas Zou et al. (2013) evaluated the adsorption of the synthetic dyes, neutral red and malachite green, onto GP reaching the equilibrium with a removal of $64.03 \%$ and $62.98 \%$, respectively.

In this study, the most widely used models pseudo-first order equation also called Langergren's kinetics equation and pseudo-second order equations (Ho and McKay, 1998) were employed to analyse kinetics of the adsorptive removal of

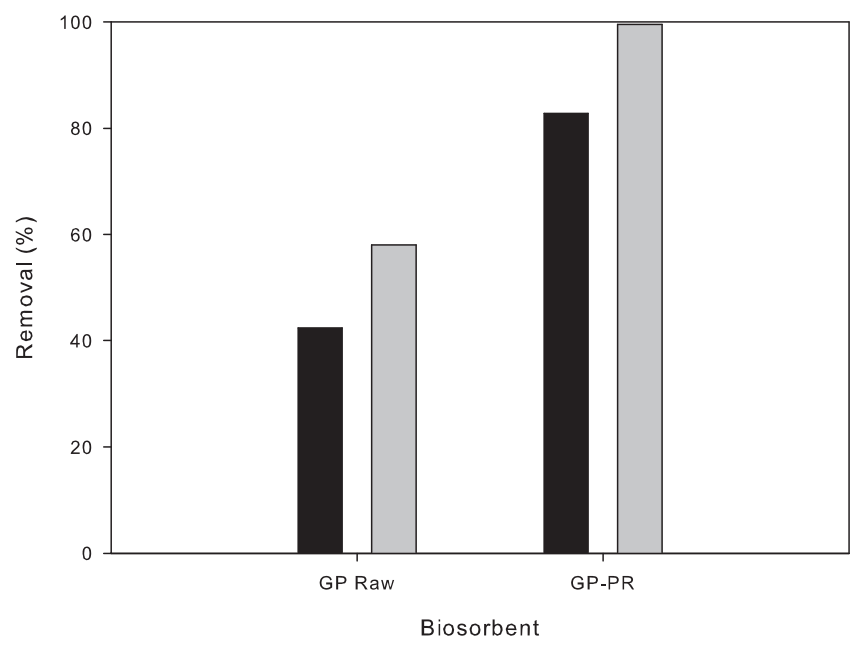

Fig. 2 - Maximum DM (black) and Cr(VI) (grey) removal percentage by adsorption of raw and pretreated $\left(\mathrm{H}_{2} \mathrm{O}_{2} 1 \mathrm{M}\right)$ GP. Initial conditions: $\mathrm{Cr}(\mathrm{VI})$ concentration $35 \mathrm{mg} / \mathrm{L}$; DM concentration $200 \mathrm{mg} / \mathrm{L}$; biosorbent $1 \mathrm{~g}$. 
$\mathrm{DM}$ and $\mathrm{Cr}(\mathrm{VI})$ onto the different biosorbents. The larger differences between experimental and calculated $q_{e}$ values indicated that the pseudo-first order model did not fit well for the DM. However, it was found a better agreement between the experimental values and the model when a pseudo-second order kinetic was considered. Contrary behaviour was found in the adsorption experiments of $\mathrm{Cr}(\mathrm{VI})$, and pseudo-first order kinetics fitted well to experimental data for all biosorbents studied. Although the kinetic studies verified that GP is a promising biosorbent, the removal percentage achieved was lesser than $60 \%$ for both pollutants. In order to improve adsorption ability of GP and avoid the possible interferences in any future measures due to colour release by the biosorbent, the effect of the pretreatment with $\mathrm{H}_{2} \mathrm{O}_{2}$ on GP adsorption ability was evaluated.

\subsection{Pretreatment of the biosorbent}

Modification of biosorbents by different pretreatment methods increases the adsorption abilities through modification of their structure and sites responsible for the binding. Thus, the adsorption properties of biosorbents vary with the pretreatment agent concentration and the pollutant considered. Different pretreatment methods are available in the literature, but in this study $\mathrm{H}_{2} \mathrm{O}_{2}$ has been proposed to avoid the release of colour in biosorbents such as orange or grapefruit peelings (Chen et al., 2012).

As can be seen in Fig. 2, the pretreatment using $\mathrm{H}_{2} \mathrm{O}_{2}$ (1 M) implied a sharply increase in $\mathrm{DM}$ and $\mathrm{Cr}(\mathrm{VI})$ removal in comparison with the raw material, reaching near complete removal of $\mathrm{Cr}(\mathrm{VI})$ and nearly $80 \%$ for $\mathrm{DM}$. The effect of increasing $\mathrm{H}_{2} \mathrm{O}_{2}$ concentration in the pretreatment of GP was also considered. However, when the pretreatment was done using $10 \mathrm{M}$ of $\mathrm{H}_{2} \mathrm{O}_{2}$, there was almost no modification in the removal (data not shown). However, the use of this high concentration of $\mathrm{H}_{2} \mathrm{O}_{2}$ reduced significantly the amount of biomass obtained after the pretreatment. These results are in accordance with those exposed by Chen et al. (2012) who stated that concentrations of $\mathrm{H}_{2} \mathrm{O}_{2}>1 \mathrm{M}$ implied the degradation of the biomass and a reduction of the amount available to be used as well as an expensive cost for the pretreatment.

The selected pretreatment proved to be effective, increasing the levels of adsorption in comparison with the raw material and avoiding possible interferences in any future measures due to colour release. For this reason, this material was the selected biosorbent for the rest of the study.

\subsubsection{Characterisation of the pretreated biosorbent}

FTIR spectra were done in order to characterise the biosorbent before and after the pretreatment using $\mathrm{H}_{2} \mathrm{O}_{2} 1 \mathrm{M}$. According to Ayeni et al. (2013), the pretreatment with $\mathrm{H}_{2} \mathrm{O}_{2}$ reduces the degree of cellulose crystallinity, removes or separates hemicellulose from cellulose and increases the accessible surface area of biomass. These facts can be observed by the small modification of the peaks at 3650-3200, 1738, 1375-1365, $1050-1010 \mathrm{~cm}^{-1}$ characteristic of cellulose, hemicellulose and lignin (Fig. 3). No new peaks appeared in the FTIR spectra suggesting that $\mathrm{H}_{2} \mathrm{O}_{2}$-modified sample remains very close to raw GP, suggesting that $\mathrm{H}_{2} \mathrm{O}_{2}$ influence on the chemical composition of the $\mathrm{H}_{2} \mathrm{O}_{2}$-modified sample is minimal as described by Kalhori et al. (2013) using LECA as biosorbent.

The pretreated biosorbent showed an adsorption capacity of $1.1003 \mathrm{meq} / \mathrm{g}$ for the different reaction sites (acidic surface groups and basic surface groups). These groups were



Fig. 3 - FTIR spectra of raw GP (-), $\mathrm{H}_{2} \mathrm{O}_{2} 1 \mathrm{M}$ pretreated GP (...).

Table 2 - Functional groups in the pretreated grapefruit peelings (Boehm method).

\begin{tabular}{lc}
\hline Functional groups & $\mathrm{meq} / \mathrm{g}$ \\
\hline Acidic surface groups & \\
Carboxylic & 0.3925 \\
Lactonic & 0.3395 \\
Phenolic & 0.1698 \\
Basic surface groups & 0.1985 \\
\hline
\end{tabular}

quantified using the Boehm assay. As it is shown in Table 2, a high amount of acidic surface groups were detected.

The surface chemistry of the biosorbent is a significant factor in the adsorption process, and it can be determined using the point of zero charge ( $\mathrm{pH}_{\mathrm{PZC}}$ ). The charge on the surface of the biosorbent may be negative, positive or neutral, and it influences the adsorption process. The obtained $\mathrm{pH}_{\mathrm{PzC}}$ was 3.48 , and this implies that the surface charge was negative at the studied $\mathrm{pH}$.

\subsubsection{Effect of the biosorbent dosage}

The removal percentage of $\mathrm{DM}$ and $\mathrm{Cr}(\mathrm{VI})$ as a function of pretreated GP dosage is presented in Fig. 4. Adsorption experiments were carried out with an initial concentration of 200 and $35 \mathrm{mg} / \mathrm{L}$ for $\mathrm{DM}$ and $\mathrm{Cr}(\mathrm{VI})$, respectively, and biosorbent dosage was $0.3-1.5 \mathrm{~g}$. The maximum removals of DM (85.03\%) and $\mathrm{Cr}(\mathrm{VI})(99.95 \%)$ were reached when $1 \mathrm{~g}$ of biosorbent was employed.

According to the literature, the profile shown in Fig. 4 clearly indicates that the increase of the pollutant adsorption was possible when the biosorbent mass was increased up to a value of $1 \mathrm{~g}$ of pretreated GP, due to the actives sites available were augmented. However, a reduction on the adsorption removal was detected when the biosorbent dosage was higher than $1 \mathrm{~g}$. This fact could be explained by the partial aggregation of biomass resulting in a lower effective surface area (Bayo et al., 2012). From the results obtained, it was established that the biosorbent mass of $1 \mathrm{~g}$ showed the best performance for the aim of this study, and further studies were developed keeping this amount of biosorbent. 


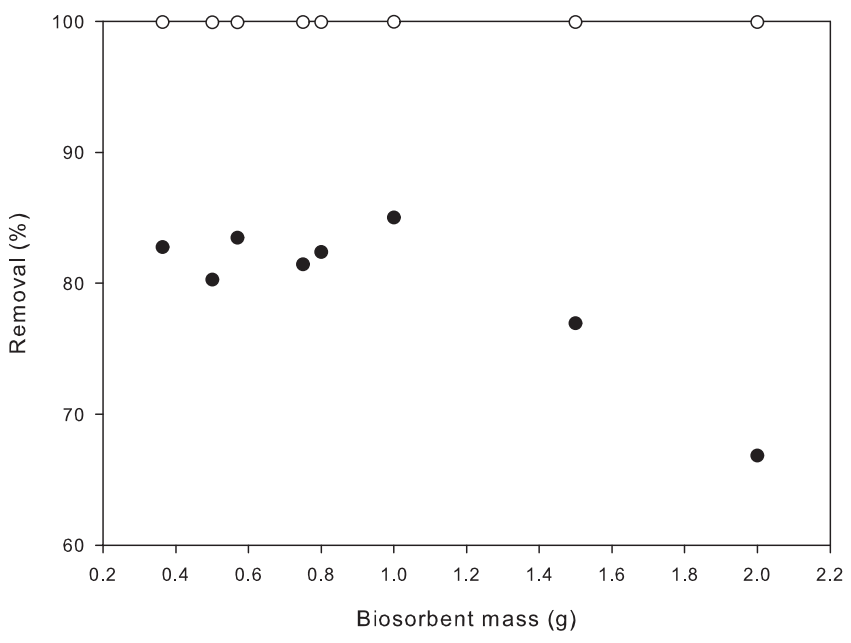

Fig. 4 - Effect of biosorbent dosage on the removal of DM (black circle) and $\mathrm{Cr}(\mathrm{VI})$ (white circle).
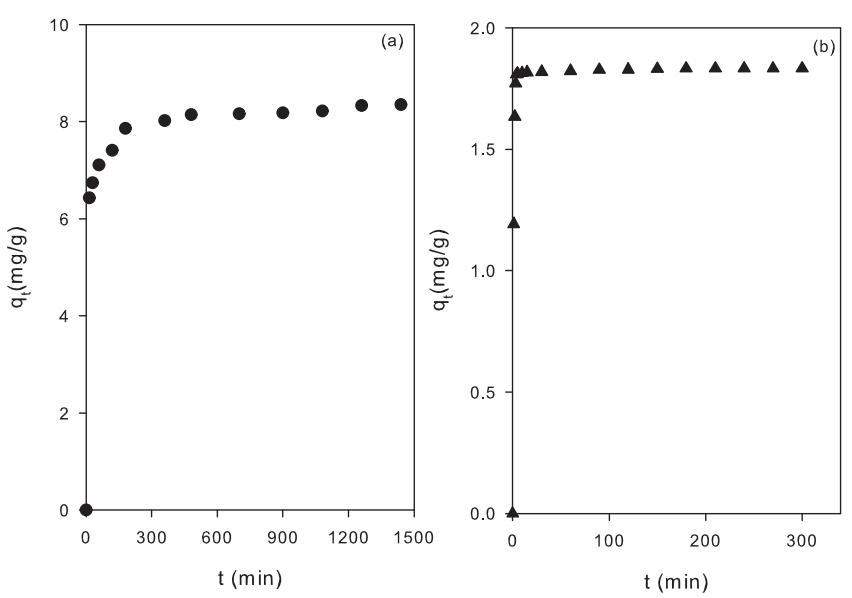

Fig. 5 - Effect of contact time on the adsorption of (a) $\mathrm{Cr}(\mathrm{VI})$ and (b) DM onto pretreated GP.

\subsubsection{Effect of the contact time}

To determine the effect of contact time between the pretreated GP and the pollutants, their uptakes were evaluated along the time. Fig. 5 illustrates that the DM adsorption process was a fast process where $>95 \%$ of the adsorption took place within the first $10 \mathrm{~min}$ reaching equilibrium after less than $100 \mathrm{~min}$. This fact demonstrated that the pretreatment improves the adsorption ability of the GP in comparison with the raw material where $24 \mathrm{~h}$ were required to reach the equilibrium. The $\mathrm{Cr}(\mathrm{VI})$ adsorption also reduced the time required to complete the process, attaining the equilibrium at approximately $400 \mathrm{~min}$.

\subsubsection{Adsorption isotherms}

Adsorption isotherms allow to determinate the surface properties of the biosorbents and are important for the description of the interaction between the molecules of adsorbate and biosorbent surface and the concentration of dissolved adsorbate in the liquid at equilibrium.

Different models have been described in the literature to relate the experimental data with the isotherms including several two- or three-parameter models. Different two-parameter models, Langmuir and Freundlich, and three-parameter models, Sips and Redlich, have been selected in this study to analyse the adsorption mechanisms and characteristic parameters of the process. In order to determine the sorption mechanism, the obtained data were fitted to the selected models, and the results are shown in Table 3.

As is shown in Table 1, similar correlations between the experimental data and the different isotherm models were determined. The Langmuir isotherm model fitted well to experimental data for both pollutants with $r^{2} \geq 0.98$. The monolayer saturation capacities of pretreated GP were found to be $37.4270 \mathrm{mg}$ of DM/g of GP and $39.0628 \mathrm{mg}$ of $\mathrm{Cr}(\mathrm{VI}) / \mathrm{g}$ of GP. These values are higher than the reported by Cobas et al. (2014) for the same mixture of dyes using as biosorbent $F$. vesiculosus, and the $\mathrm{Cr}(\mathrm{VI})$ uptake values were drastically higher than the reported for other lignocellulosic wastes such as hazelnut, F. vesiculosus, C. esculenta and similar to those reported for sawdust (working at very acidic $\mathrm{pH}$ ) (Table 4).

In addition, a dimensionless constant separation factor, $R_{\mathrm{L}}$, can be used to express essential characteristics of Langmuir isotherm, which is given by

$R_{L}=\frac{1}{\left(1+K_{L} C_{i}\right)}$

The nature of the biosorption was determined by the value of separation factor $R_{\mathrm{L}}$. The value of $R_{\mathrm{L}}$ indicates the type of isotherm to be unfavourable when $R_{\mathrm{L}}>1$, linear when $R_{\mathrm{L}}=1$, favourable when $0<R_{\mathrm{L}}<1$ and irreversible when $R_{\mathrm{L}}=0$ (Guyo et al., 2015; Iglesias et al., 2013). The calculated values for the different pollutants were close to 0 , which was indicative for a favourable adsorption of both pollutants.

The results obtained for fitting the Langmuir and Freundlich models to the data of DM adsorption were similar, so that it was not possible determined the type of interaction among the molecules and the biosorbents using these models. Thus, the use of three-parameter models was required. The value of the obtained coefficients $\beta_{\mathrm{S}}$ and $\beta_{\mathrm{RP}}$ suggested that the behaviour did not correspond to pure homogeneous but it is close to Langmuir model. On the other hand, when Redlich and Sips three-parameter models were also fitted to the $\mathrm{Cr}(\mathrm{VI})$ data, the expressions were reduced to Langmuir form. This suggests that the biosorbent behave as structurally homogeneous surface in the adsorption process of the $\mathrm{Cr}(\mathrm{VI})$ anion. This fact has been demonstrated using SEM-EDS (Fig. 6).

To determine the effect of the different surface groups in the adsorption processes, the pretreated GP has been esterified or methylated, and new adsorption assays were developed. The removal of the carboxylic acids conducted to a decrease in the uptake levels for DM around $25 \%$ but none for $\mathrm{Cr}(\mathrm{VI})$. However, the methylation of the biosorbent did not produce a decrease in the adsorption of none of the studied pollutants. These facts suggest that the carboxylic groups are mainly involved in the removal of the DM. The determination of the surface groups involved in the $\mathrm{Cr}(\mathrm{VI})$ removal is difficult to identify; we can postulate that $\mathrm{Cr}(\mathrm{VI})$ are linked to the basic surface groups. This fact is in accordance with the speciation of the $\mathrm{Cr}(\mathrm{VI})$. As is depicted in Fig. 7, different ratios of anionic monovalent and divalent species of $\mathrm{Cr}(\mathrm{VI})$ can be present at natural pH 5.5.

\subsubsection{Adsorption kinetics and mechanism}

The development of different applications of the system requires the determination of operational and kinetic parameters. They provide us valuable insights into the reaction mechanism of the reaction. 
Table 3 - Parameters of the isotherms models obtained for the different pollutants.

\begin{tabular}{|c|c|c|c|}
\hline & Parameters & DM & $\mathrm{Cr}(\mathrm{VI})$ \\
\hline \multirow[t]{3}{*}{ Langmuir $q=q_{\max } \cdot b_{L} \cdot C /\left(1+b_{L} \cdot C\right)[$ Eq. (3)] } & $q_{\max }$ & 37.4270 & 39.0628 \\
\hline & $b_{\mathrm{L}}$ & 0.0096 & 2.8631 \\
\hline & $r^{2}$ & 0.9830 & 0.9802 \\
\hline \multirow[t]{3}{*}{ Freundlich $q=K_{F} \cdot C^{1 / n_{F}}$ [Eq. (4)] } & $K_{\mathrm{F}}$ & 0.8152 & 76.6809 \\
\hline & $1 / n_{F}$ & 0.6866 & 0.9185 \\
\hline & $r^{2}$ & 0.9828 & 0.9784 \\
\hline \multirow{4}{*}{ Sips $q=K_{\mathrm{S}} \cdot C^{\beta} \mathrm{S} /\left(1+a_{\mathrm{S}} \cdot C^{\beta} \mathrm{S}\right)$ [Eq. (5)] } & $\mathrm{K}_{\mathrm{S}}$ & 0.5017 & 111.8408 \\
\hline & $\beta_{\mathrm{S}}$ & 0.8786 & 1.0000 \\
\hline & $a_{\mathrm{S}}$ & 0.0094 & 2.8631 \\
\hline & $r^{2}$ & 0.9832 & 0.9802 \\
\hline \multirow[t]{4}{*}{ Redlich $q=K_{\mathrm{RP}} \cdot C /\left(1+a_{\mathrm{RP}} \cdot C^{\beta_{\mathrm{RP}}}\right)$ [Eq. (6)] } & $K_{\mathrm{RP}}$ & 0.4217 & 111.8408 \\
\hline & $\beta_{\mathrm{RP}}$ & 0.7558 & 1.0000 \\
\hline & $a_{\mathrm{RP}}$ & 0.0388 & 2.8631 \\
\hline & $r^{2}$ & 0.9831 & 0.9802 \\
\hline
\end{tabular}

Table 4 - Uptakes obtained for different biosorbents in the removal of dyes and heavy metals.

\begin{tabular}{|c|c|c|c|c|}
\hline Waste & Pollutant & Uptake (mg/g) & $\mathrm{pH}$ & Reference \\
\hline \multirow[t]{2}{*}{ Lemon peelings } & Methyl Orange & 50.3 & $5.5-6.5$ & Bhatnagar et al. (2009) \\
\hline & Congo Red & 34.5 & & \\
\hline Fucus vesiculosus & $\begin{array}{l}\text { Sella Solid Blue, Special Violet, Derma } \\
\text { Burdeaux, and Sella Solid Orange }\end{array}$ & 27.01 & 6 & Cobas et al. (2014) \\
\hline Grapefruit peelings & $\begin{array}{l}\text { Sella Solid Blue, Special Violet, Derma } \\
\text { Burdeaux, and Sella Solid Orange }\end{array}$ & 37.43 & 5.5 & This work \\
\hline \multirow[t]{2}{*}{ Grapefruit peeling } & $\mathrm{Cd}(\mathrm{II})$ & 42.09 & & Torab-Mostaedi et al. (2013) \\
\hline & $\mathrm{Ni}(\mathrm{II})$ & 46.13 & & \\
\hline Grapefruit peelings & $\mathrm{Cr}(\mathrm{VI})$ & 39.06 & 5.5 & This work \\
\hline Hazelnut & $\mathrm{Cr}(\mathrm{VI})$ & 8.28 & 5 & Pakshirajan et al. (2013) \\
\hline Sawdust & $\mathrm{Cr}(\mathrm{VI})$ & 41.5 & 1 & Pakshirajan et al. (2013) \\
\hline Fucus vesiculosus & $\mathrm{Cr}(\mathrm{VI})$ & 2.519 & 6 & Cobas et al. (2014) \\
\hline Colocasia esculenta & $\mathrm{Cr}(\mathrm{VI})$ & 1.42 & $4.5-5.5$ & Pakshirajan et al. (2013) \\
\hline
\end{tabular}

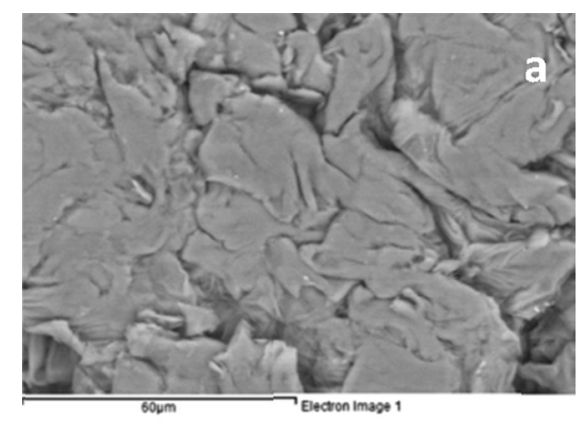

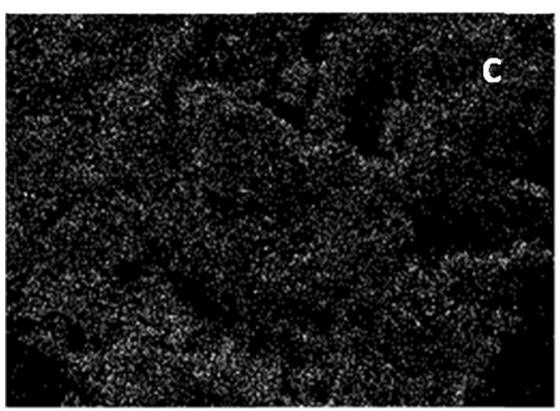

O Ka1

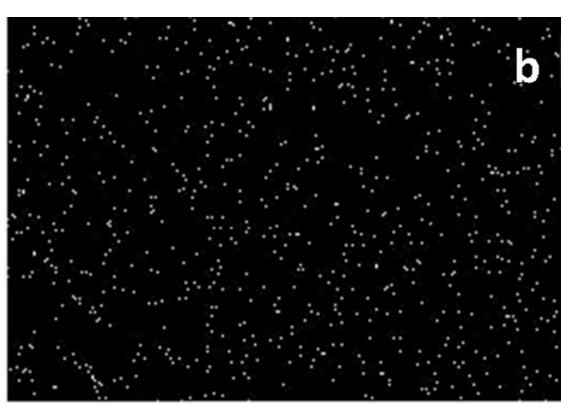

CrKa1

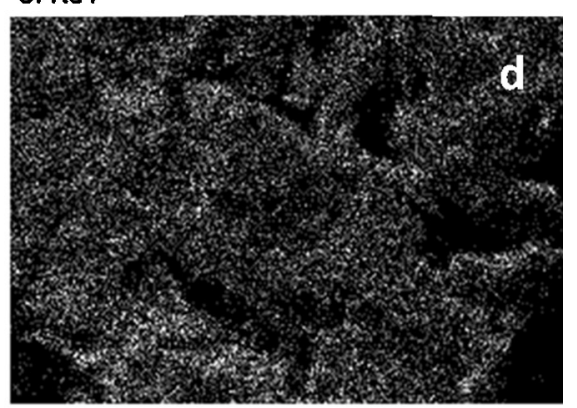

CKa1_2

Fig. 6 - SEM image (a) and EDS mapping (b-d) of the pretreated biosorbent after the chromium adsorption. (b) Chromium distribution, (c) oxygen distribution and (d) carbon distribution on the biosorbent.

The data obtained for the adsorption of DM and $\mathrm{Cr}(\mathrm{VI})$ with the pretreated GP were evaluated using pseudo-first and pseudo-second order equations and consequent parameters were calculated (Table 5). The pseudo-first order fitted well to the $\mathrm{Cr}(\mathrm{VI})$ adsorption onto the GP pretreated. According to Pérez Marín et al. (2009), the assumption of the uptake rate limited to a homogeneous surface by a single mechanism can be done. The maximum uptake capacity for $\mathrm{Cr}(\mathrm{VI})$ adsorption was $1.828 \mathrm{mg} / \mathrm{g}$. On the other hand, when adsorption of DM onto biosorbent was analysed, the adsorption was 
Table 5 - Kinetic parameters obtained for the removal of $\mathrm{Cr}(\mathrm{VI})(35 \mathrm{mg} / \mathrm{L})$ and $\mathrm{DM}(200 \mathrm{mg} / \mathrm{L})$ with pretreated GP.

\begin{tabular}{llccccccc} 
& \multicolumn{3}{c}{ Pseudo-first order } & & \multicolumn{3}{c}{ Pseudo-second order } \\
\cline { 2 - 3 } & $q_{e}(\mathrm{mg} / \mathrm{g})$ & $k_{1}(1 / \mathrm{min})$ & $r^{2}$ & & $q_{e}(\mathrm{mg} / \mathrm{g})$ & $k_{2}(\mathrm{~g} / \mathrm{mg} \min )$ & $r^{2}$ \\
\hline DM adsorption & 7.9186 & 0.0960 & 0.9638 & & 8.1500 & 0.0239 & 0.9895 \\
Cr(VI) adsorption & 1.8280 & 1.0820 & 0.9996 & & 1.8587 & 1.4655 & 0.9795 \\
\hline
\end{tabular}



Fig. 7 - $\mathrm{Cr}$ (VI) speciation in the $\mathrm{pH}$ range of adsorption (data obtained based on software Visual MINTEQ).

well described by pseudo-second order kinetic model. This fact suggests that chemisorption may be the rate-limiting for this process, and the adsorption process is related to a heterogeneous surface for DM uptake.

The identification of the mechanisms involved in the adsorption process cannot be performed using the previously described kinetics models. Among the different available models, intraparticle diffusion is commonly used for this purpose of identifying the adsorption mechanism.

The effect of intraparticle diffusion resistance on adsorption can be determined fitting the data to the expression to

$q_{t}=k_{\text {id }} \cdot t^{0.5}+I$

The obtained results (Fig. 8) showed that the regression is not linear over the whole time range, but can be divided into a few linear regions. The fact that none of these linear segments intersects the origin indicated that there was more than one rate-controlling step and not only the intraparticle diffusion (Rosales et al., 2012).

For DM and $\mathrm{Cr}(\mathrm{VI})$, three linear segments are evident, and the slopes of the segment indicated the rates of the adsorption during the three stages: $k_{\mathrm{id} 1} 0.1422\left(\mathrm{mg} / \mathrm{g} \mathrm{min}^{0.5}\right), k_{\mathrm{id} 2}$ $0.0324\left(\mathrm{mg} / \mathrm{g} \mathrm{min}^{0.5}\right)$ and $k_{\mathrm{id} 3} 0.0136\left(\mathrm{mg} / \mathrm{g} \mathrm{min}^{0.5}\right)$ for DM; $k_{\mathrm{id} 1}$ $0.8049\left(\mathrm{mg} / \mathrm{g} \mathrm{min}^{0.5}\right), k_{\mathrm{id} 2} 0.0027\left(\mathrm{mg} / \mathrm{g} \mathrm{min}^{0.5}\right)$ and $k_{\mathrm{id} 3} 0.0012$ $\left(\mathrm{mg} / \mathrm{g} \mathrm{min}^{0.5}\right)$ for $\mathrm{Cr}(\mathrm{VI})$. Lorenc-Grabowska and Gryglewicz (2007) suggested that the first segment with the sharper slope and high kinetic constant may be related with the diffusion of adsorbate through the solution to the external surface of biosorbent or the boundary layer diffusion of solute molecules; in the second segment, they proposed that the intraparticle diffusion rate is rate-limiting process in a gradual adsorption stage, and the last segment with the lowest kinetic constants corresponded to a final equilibrium stage where the intraparticle diffusion starts to slow down due to the extremely low

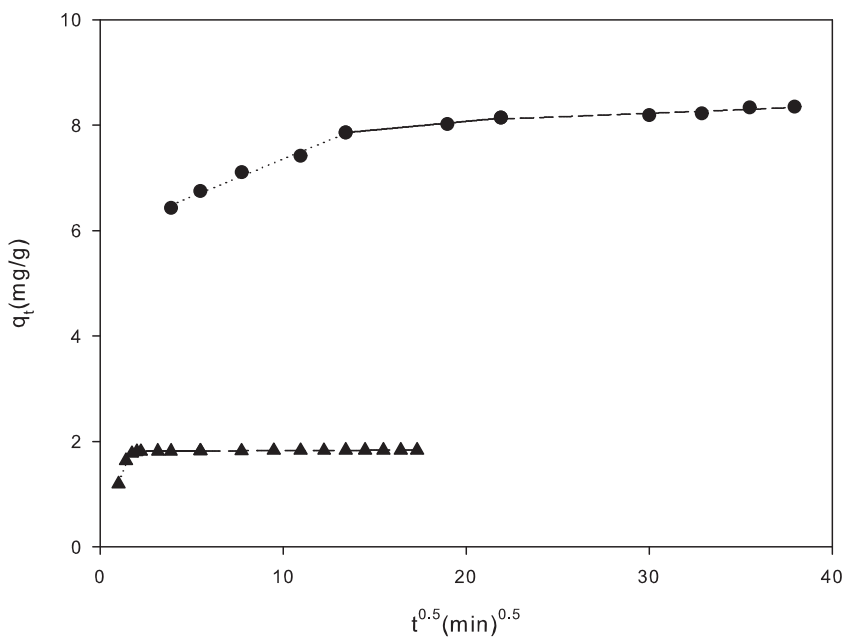

Fig. 8 - Plot of the experimental data fitted to the intraparticle diffusion model for the adsorption of $\mathrm{Cr}(\mathrm{VI})$ (black triangle) and DM (black circle).

adsorbate concentration left in the solution. Therefore, surface adsorption and intraparticle diffusion contribute to the metal and DM adsorption.

\subsection{Breakthrough curves}

To design an adsorption column, it is necessary to know information about the dynamic behaviour of the pollutant concentration present in the effluent along the time. This process occurs in systems where the solution containing the biosorbent passes continuously through a fixed packed-bed column filled with the biosorbent. Breakthrough curves are, therefore, required and provide information for a practical application of column adsorption.

Experimentation and mathematical modelling are the more commonly used approaches to obtain the breakthrough curves of a system. Among them, experimental method is usually a time-consuming and economical undesirable process; however, theoretical models become an affordable, valuable time and cost-reducing solution to solve this problem and predict the dynamic behaviour of the column in biosorption processes (Ramirez et al., 2007).

In this study, a pilot plant with a column for adsorption of height $1.5 \mathrm{~m}$, volume $100 \mathrm{~L}$ and internal diameter $0.3 \mathrm{~m}$ was simulated. A dynamic behaviour of the system, operating at different flow rates, was simulated using a HSDM. The parameters used in the simulation are described in Table 6.

The film diffusion coefficient $K_{\mathrm{L}}$ value was calculated based on dimensional number Sherwood:

$S h=\frac{K_{\mathrm{L}} \cdot d_{\mathrm{p}}}{D_{\mathrm{s}}}$ 
Table 6 - Parameters considered for analysing the model using FAST 1.1.

Operational parameters

\begin{tabular}{|c|c|c|c|c|}
\hline \multirow[t]{2}{*}{$m_{\text {ads }}(\mathrm{kg})$} & 75 & $D_{\mathrm{s}}\left(\mathrm{m}^{2} / \mathrm{s}\right)$ & $\mathrm{DM}$ & $1.04 \times 10^{-12^{* *}}$ \\
\hline & & & $\mathrm{Cr}(\mathrm{VI})$ & $0.82 \times 10^{-12^{* * *}}$ \\
\hline$\varepsilon$ & 0.3944 & Langmuir DM & $q_{\max }$ & 37.4270 \\
\hline$\rho_{\mathrm{p}}$ & 1.25 & & $b_{\mathrm{L}}$ & 0.0096 \\
\hline$d_{p}$ & 0.5 & Langmuir $\mathrm{Cr}(\mathrm{VI})$ & $q_{\max }$ & 39.0628 \\
\hline $\mathrm{V}_{\mathrm{C}}(\mathrm{L})^{*}$ & 100 & & $b_{\mathrm{L}}$ & 2.8631 \\
\hline \multirow[t]{2}{*}{$h(\mathrm{~m})^{*}$} & 1.5 & $C_{i}$ & $\mathrm{DM}$ & 200 \\
\hline & & & $\mathrm{Cr}(\mathrm{VI})$ & 35 \\
\hline$D_{\mathrm{C}}(\mathrm{m})^{*}$ & 0.3 & $\mathrm{~K}_{\mathrm{L}}$ & \multicolumn{2}{|c|}{ Determined by Eqs. (9) and (10) } \\
\hline
\end{tabular}

* Pazos et al. (2010).

** Lin and Leu (2008)

*** Lin et al. (2011).
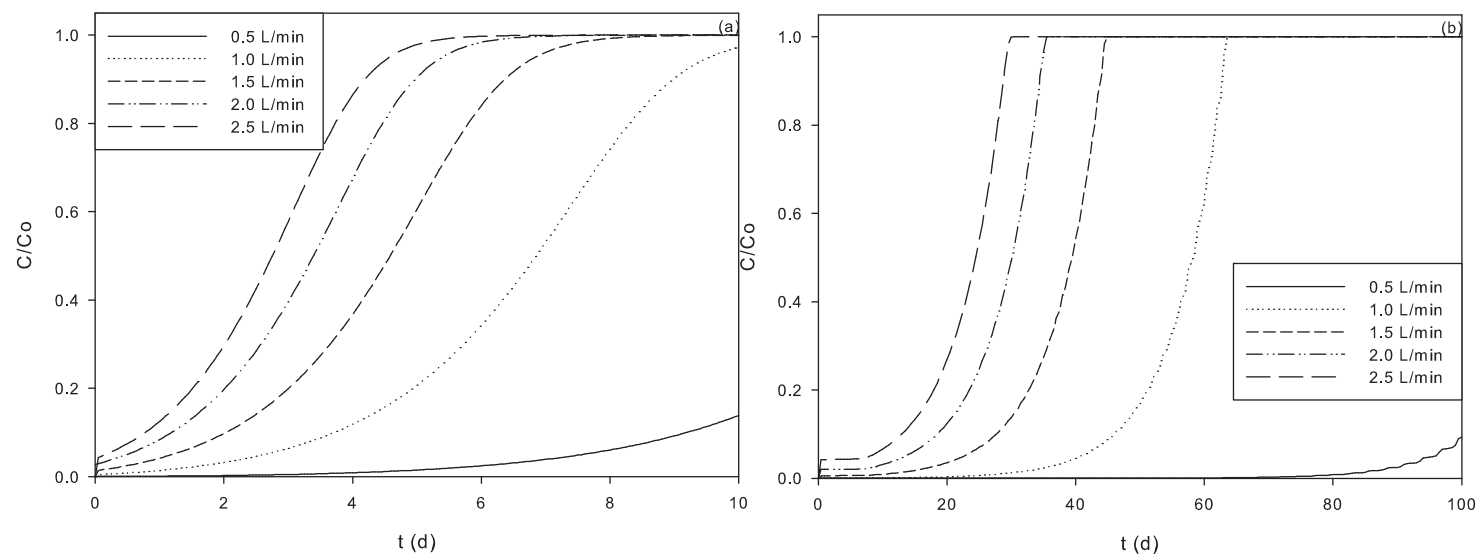

Fig. 9 - Breakthrough curves obtained from the simulation at different flow rates: (a) DM adsorption, (b) Cr(VI) adsorption.

and the sherwood number was calculated based on the expression (Ohashi et al., 1981) knowing Reynolds, $\operatorname{Re}=\rho_{w} \cdot v \cdot d_{50} / \mu_{w}, \mathrm{Schmidt}, \mathrm{Sc}=\mu_{w} / \rho_{w} \cdot \mathrm{D}_{m}$ :

$\mathrm{Sh}=2+1.1 \cdot R e^{0.6} \cdot \mathrm{Sc}^{0.33}$

The effect of the flow rates in the breakthrough curve was studied, and the simulated breakthrough curves are shown in Fig. 9. The comparison of these obtained breakthrough curves indicated that the operation time under which no pollutant is detected in the outflow depends on the pollutant interval time in which is completely sorbed. DM was the first pollutant in saturating the biosorbent followed by $\mathrm{Cr}(\mathrm{VI})$. As the flow rate increased, breakthrough time was obtained earlier, and shorter time was required for completely saturating the biosorbent with the adsorbate, and therefore a replacement or regeneration. These results are in accordance with the exposed by Escudero et al. (2013).

The estimation of time for the biosorbent exhaustion was also done by HSDM. Considering the criteria that this point was reached when the effluent concentration reached $90 \%$ of the initial value, the biosorbent would be exhausted at 9 , 6.4, 5, 4.2 days for DM and 62.5, 44, 34.5, 29 days for $\mathrm{Cr}(\mathrm{VI})$ working with a flow rate values were $0.5,1,1.5,2,2.5 \mathrm{~L} / \mathrm{min}$, respectively.

\section{Conclusions}

Several agroforestry wastes were evaluated for the removal of a mixture of industrial leather dyes and $\mathrm{Cr}(\mathrm{VI})$ at natural
pH. Among them, the highest adsorption capacities for the selected pollutants were obtained when GP was used. The performance of the selected biosorbent showed a significant improvement when it was pretreated with $\mathrm{H}_{2} \mathrm{O}_{2}(1 \mathrm{M})$ reaching high levels of uptake, $q_{\max }$ of 37.4270 and $39.0628 \mathrm{mg} / \mathrm{g}$ for $\mathrm{DM}$ and $\mathrm{Cr}(\mathrm{VI})$, respectively. The characterisation of this biosorbent demonstrated the presence of acidic and basic surface groups as linking points for the pollutants. Adsorption kinetics fitted to a pseudo-first order for $\mathrm{Cr}(\mathrm{VI})$ and pseudosecond order for DM. Langmuir isotherm model fitted the data better than the other considered models for $\mathrm{DM}$ and $\mathrm{Cr}(\mathrm{VI})$ adsorption. This fact was in accordance with SEM images which confirmed a homogeneous $\mathrm{Cr}(\mathrm{VI})$ distribution on the surface of the biosorbent. Finally, a continuous adsorption treatment was modelled on the basis of biosorbent characteristics and using a HSDM model. The feasibility of the developed process demonstrates the versatility of pretreated GP as a biosorbent for the remediation of the complex medium as evaluated in this study.

\section{Acknowledgments}

This work has been funded by the Spanish Ministry of Economy and Competitiveness, Xunta de Galicia and ERDF Funds (Projects CTM 2011-25389 and GRC 2013/003). The authors are grateful to Xunta de Galicia for financial support of the researcher Emilio Rosales under a postdoctoral grant and the Spanish Ministry of Economy and Competitiveness for financial support of the researcher Marta Pazos under a Ramón y Cajal grant. 


\section{References}

Acar, F.N., Malkoc, E., 2004. The removal of chromium(VI) from aqueous solutions by Fagus orientalis L. Bioresour. Technol. 94, 13-15.

Ayeni, A.O., Hymore, F.K., Mudliar, S.N., Deshmukh, S.C., Satpute, D.B., Omoleye, J.A., Pandey, R.A., 2013. Hydrogen peroxide and lime based oxidative pretreatment of wood waste to enhance enzymatic hydrolysis for a biorefinery: Process parameters optimization using response surface methodology. Fuel 106, 187-194.

Bayo, J., Esteban, G., Castillo, J., 2012. The use of native and protonated grapefruit biomass (Citrus paradisi L.) for cadmium(II) biosorption: equilibrium and kinetic modelling. Environ. Technol. 33, 761-772.

Bhatnagar, A., Kumar, E., Minocha, A.K., Jeon, B.-H., Song, H., Seo, Y.-C., 2009. Removal of anionic dyes from water using Citrus limonum (lemon) peel: equilibrium studies and kinetic modeling. Sep. Sci. Technol. 44, 316-334.

Bhatnagar, A., Sillanpää, M., Witek-Krowiak, A., 2015. Agricultural waste peels as versatile biomass for water purification-a review. Chem. Eng. J. 270, 244-271.

Boehm, H.P., 1966. Chemical identification of surface groups. Adv. Catal. 16, 179-274.

Carrier, M., Loppinet-Serani, A., Absalon, C., Aymonier, C., Mench, M., 2012. Degradation pathways of holocellulose, lignin and a-cellulose from Pteris vittata fronds in sub- and super critical conditions. Biomass Bioenergy 43, 65-71.

Chen, S., Luo, J., Hu, M., Lai, K., Geng, P., Huang, H., 2012. Enhancement of cypermethrin degradation by a coculture of Bacillus cereus ZH-3 and Streptomyces aureus HP-S-01. Bioresour. Technol. 110, 97-104.

Cobas, M., Sanromán, M.A., Pazos, M., 2014. Box-Behnken methodology for $\mathrm{Cr}$ (VI) and leather dyes removal by an eco-friendly biosorbent: F. vesiculosus. Bioresour. Technol. 160, 166-174.

Crini, G., 2006. Non-conventional low-cost adsorbents for dye removal: a review. Bioresour. Technol. 97, 1061-1085.

Daffalla, S.B., Mukhtar, H., Shaharun, M.S., 2012. Effect of organic and inorganic acid pretreatment on structural properties of rice husk and adsorption mechanism of phenol. Int. J. Chem. Env. Eng. 3, 192-200.

Deshkar, A.M., Bokade, S.S., Dara, S.S., 1990. Modified Hardwickia binata bark for adsorption of mercury(II) from water. Water Res. 24, 1011-1016.

Escudero, C., Poch, J., Villaescusa, I., 2013. Modelling of breakthrough curves of single and binary mixtures of $\mathrm{Cu}(\mathrm{II})$, $\mathrm{Cd}(\mathrm{II}), \mathrm{Ni}(\mathrm{II})$ and $\mathrm{Pb}$ (II) sorption onto grape stalks waste. Chem. Eng. J. 217, 129-138.

Gaitán-Hernández, R., Esqueda, M., Gutiérrez, A., Beltrán-García, M., 2011. Quantitative changes in the biochemical composition of lignocellulosic residues during the vegetative growth of Lentinula Edodes. Braz. J. Microbiol. 42, 30-40.

Gardea-Torresdey, J.L., 1990. Effect of chemical modification of algal carboxyl groups on metal ion binding. ESandT Contents 24, 1372-1378.

Gupta, V.K., Carrott, P.J.M., Ribeiro Carrott, M.M.L., Suhas, 2009. Low-cost adsorbents: growing approach to wastewater treatment a review. Crit. Rev. Environ. Sci. Technol. 39, 783-842.

Guyo, U., Mhonyera, J., Moyo, M., 2015. Pb(II) adsorption from aqueous solutions by raw and treated biomass of maize stover-a comparative study. Process Saf. Environ. Prot. 93, 192-200.

Ho, Y.S., McKay, G., 1998. A comparison of chemisorption kinetic models applied to pollutant removal on various sorbents. Process Saf. Environ. Prot. 76, 332-340.

Hossain, M.A., Ngo, H.H., Guo, W.S., Nguyen, T.V., Vigneswaran, S., 2014. Performance of cabbage and cauliflower wastes for heavy metals removal. Desalin. Water Treat. 52, 844-860.

Iglesias, O., Fernández de Dios, M.A., Pazos, M., Sanromán, M.A., 2013. Using iron-loaded sepiolite obtained by adsorption as a catalyst in the electro-Fenton oxidation of Reactive Black 5. Environ. Sci. Pollut. Res. 20, 5983-5993.

Kalhori, E.M., Yetilmezsoy, K., Uygur, N., Zarrabi, M., Shmeis, R.M.A., 2013. Modeling of adsorption of toxic chromium on natural and surface modified lightweight expanded clay aggregate (LECA). Appl. Surf. Sci. 287, 428-442.

Lin, Y.-H., Leu, J.-Y., 2008. Kinetics of reactive azo-dye decolorization by Pseudomonas luteola in a biological activated carbon process. Biochem. Eng. J. 39, 457-467.

Lin, Y.-H., Wu, C.-L., Li, H.-L., Hsu, C.-H., 2011. Verification of model for adsorption and reduction of chromium(VI) by Escherichia coli 33456 using chitosan bead as a supporting medium. Appl. Math. Model. 35, 2736-2751.

Lorenc-Grabowska, E., Gryglewicz, G., 2007. Adsorption characteristics of Congo Red on coal-based mesoporous activated carbon. Dyes Pigm. 74, 34-40.

Mediavilla, S., Garcia-Ciudad, A., Garcia-Criado, B., Escudero, A., 2008. Testing the correlations between leaf life span and leaf structural reinforcement in 13 species of European Mediterranean woody plants. Funct. Ecol. 22, 787-793.

Miranda, I., Gominho, J., Pereira, H., 2012. Incorporation of bark and tops in eucalyptus globulus wood pulping. BioResource 7 , 4350-4361.

Mwinyihija, M., 2010. Chapter 2: Main pollutants and environmental impacts of the tanning industry. In Mwinyihija, M. (Ed.), Ecotoxicological Diagnosis in the Tanning Industry. Springer, pp. 17-35, New York.

Ng, I.-S., Wu, X., Lu, Y., Yao, C., 2014. Trichoderma reesei cellulase complex in hydrolysis of agricultural waste of grapefruit peel and orange peel. BioResource 9, 6420-6431.

Noh, J.S., Schwarz, J.A., 1989. Estimation of the point of zero charge of simple oxides by mass titration. J. Colloid Interface Sci. 130, 157-164.

Ohashi, H., Sugawara, T., Kikuchi, K.I., Konno, H., 1981. Correlation of liquid-side mass transfer coefficient for single particles and fixed beds. J. Chem. Eng. Jpn. 14, 433-438.

Pakshirajan, K., Worku, A.N., Acheampong, M.A., Lubberding, H.J., Lens, P.N.L., 2013. Cr(III) and Cr(VI) removal from aqueous solutions by cheaply available fruit waste and algal biomass. Appl. Biochem. Biotechnol. 170, 498-513.

Pazos, M., Branco, M., Neves, I.C., Sanromán, M.A., Tavares, T., 2010. Removal of $\mathrm{Cr}(\mathrm{VI})$ from aqueous solutions by a bacterial biofilm supported on zeolite: optimisation of the operational conditions and scale-up of the bioreactor. Chem. Eng. Technol. 33, 2008-2014.

Pérez Marín, A.B., Aguilar, M.I., Meseguer, V.F., Ortuño, J.F., Sáez, J., Lloréns, M., 2009. Biosorption of chromium(III) by orange (Citrus cinensis) waste: batch and continuous studies. Chem. Eng. J. 155, 199-206.

Pérez-Foguet, A., Casoni, E., Huerta, A., 2013. Dimensionless analysis of HSDM and application to simulation of breakthrough curves of highly adsorbent porous media. J. Environ. Eng. 139, 667-676.

Ramirez, C.M., Pereira da Silva, M., Ferreira, L.S.G., Vasco, E.O., 2007. Mathematical models applied to the $\mathrm{Cr}$ (III) and $\mathrm{Cr}$ (VI) breakthrough curves. J. Hazard. Mater. 146, 86-90.

Richard, D., Delgado Núñez, M.d.L., Schweich, D., 2010. Adsorption of complex phenolic compounds on active charcoal: breakthrough curves. Chem. Eng. J. 158, 213-219.

Rosales, E., Ferreira, L., Sanromán, M.Á., Tavares, T., Pazos, M., 2015. Enhanced selective metal adsorption on optimised agroforestry waste mixtures. Bioresour. Technol. 182, 41-49.

Rosales, E., Pazos, M., Sanromán, M.A., Tavares, T., 2012. Application of zeolite-Arthrobacter viscosus system for the removal of heavy metal and dye: chromium and Azure B. Desalination 284, 150-156.

Saeed, A., Sharif, M., Iqbal, M., 2010. Application potential of grapefruit peel as dye sorbent: kinetics, equilibrium and mechanism of crystal violet adsorption. J. Hazard. Mater. 179, 564-572. 
Shen, C., Wen, Y., Kang, X., Liu, W., 2011. $\mathrm{H}_{2} \mathrm{O}_{2}$-induced surface modification: a facile, effective and environmentally friendly pretreatment of chitosan for dyes removal. Chem. Eng. J. 166, 474-482.

Sperlich, A., Schimmelpfennig, S., Baumgarten, B., Genz, A., Amy, G., Worch, E., Jekel, M., 2008. Predicting anion breakthrough in granular ferric hydroxide (GFH) adsorption filters. Water Res. 42, 2073-2082.

Torab-Mostaedi, M., Asadollahzadeh, M., Hemmati, A., Khosravi, A., 2013. Equilibrium, kinetic, and thermodynamic studies for biosorption of cadmium and nickel on grapefruit peel. J. Taiwan Inst. Chem. Eng. 44, 295-302.

Vijayaraghavan, K., Yun, Y.-S., 2008. Bacterial biosorbents and biosorption. Biotechnol. Adv. 26, 266-291.
Walker, H.W., 2015. Harmful Algae Blooms in Drinking Water. CRC Press, Boca Raton, FL.

Xu, G.F., Zheng, F.Z., Guo, R.X., 2014. The effects of different adsorbents from orange peel on the pesticide furadan. Adv, Mater. Res. 881-883, 584-588.

Zhang, Q., Crittenden, J., Hristovski, K., Hand, D., Westerhoff, P., 2009. User-oriented batch reactor solutions to the homogeneous surface diffusion model for different activated carbon dosages. Water Res. 43, 1859-1866.

Zou, W., Gao, S., Zou, X., Bai, H., 2013. Adsorption of neutral red and malachite green onto grapefruit peel in single and binary systems. Water Environ. Res. 85, 466-477. 